\title{
Determining Factors in Secondary School Students' Choice of Physics
}

\author{
Adegoke, B. A. ${ }^{4}$
}

\begin{abstract}
Using survey research approach, the predictive power of certain characteristics of physics curriculum, social factors, as well as some students' characteristics (11 predictor variables) on choice of physics were assessed. The study involved 384 students randomly selected from 14 public senior secondary schools in Ibadan Educational Zone I, Oyo State, Nigeria. The data generated from their responses to the "Assessing students' choice of physics" questionnaire were analyzed using standard multiple regression. Results showed that $6.9 \%$ of the variability observed in the students' choice of physics could be attributed to a linear combination of the examined predictor variables. Availability of functional science clubs in schools as well as membership of such clubs seemed to be important predictors of choice of physics. The needs for proper guidance and counselling services as well as strengthening of science clubs in schools were stressed.
\end{abstract}

Keywords: $\quad$ predictors of students' choice of physics,

\section{Introduction}

Developing countries, just like the developed nations depend to a very large extent on what science and technology could offer for the improvement of social and economic wellbeing of their citizens. Indeed, the relevance of science to national goals, aspirations and economy dictates to a large extent the huge commitment and support which most developing countries are now giving to science and technology education.

In the recent times, many developing countries (e.g. Nigeria and other African countries) have realized more than ever before, the importance of physics as a basic requirement for their economic, scientific and technological developments. The implication of this awareness is that developing countries can not develop or sustain any form of technology unless a solid foundation for effective and efficient physics education is laid. It is equally important to note that a solid foundation cannot be laid unless more secondary schools students choose to offer physics. This is so because physics is one particular subject that

4 Dr. Adegoke, B. A. is a lecturer at the Institute of Education, University of Ibadan, Ibadan. E-mail: doctoradegoke@yahoo.com. 
Determining Factors in Secondary School Students' Choice of Physics

Adegoke, B. A.

is required for many science and technology related courses such as medicine, pharmacy, engineering, computer sciences, as well as agricultural sciences among others in tertiary institutions.

Against this background, the observed decreasing interest in physics among secondary schools students in developing countries should be a ground for a serious concern to all stakeholders in the field of education. To what extent is this concern appropriate? Taking Nigeria situation as a typical example, the analysis of total students' entries and results provided by two examining bodies - West African Examination Council (WAEC) and National Examination Council (NECO) shows that the percentage of students choosing physics for their final senior secondary school certificate examination (SSCE) remained strikingly low during the past six years at an average of $29 \%$ of the total entries, while the percentage of students choosing such subjects as Economics, Biology, Commerce and Financial Accounting continued to rise. An average of 96\%; 99\%; 60; and 76\% of the total entries in economics, biology, commerce and financial accounting respectively was recorded between 2003 and 2007. More significant is that the low percentages of those choosing physics are coincident with about $10 \%$ rise in total SSCE candidates during the years in review.

The problem of low enrolment of students in physics is not peculiar to Nigeria and other developing nations of the world, in Western Europe and United States of America, the same subsists (See Gallagher, 1994; Stokking, 2000; Reid \& Skryabina, 2002; Krogh \& Thomsen, 2005; Lavonen, Byman, Juuiti, Meisalo \& Uitto, 2005; Institute of Physics, 2006). However, the impact of low level of enrolment of students in physics on science and technological developments as well as economic, social and psychological well being of the citizens tends to be more felt in the developing countries than in Europe or in the USA. Hence the observed decreased interest and enrolment of students in physics in the developing countries should indeed be of concern to educators and researchers in science education in Africa (Opara, 2006; Kuti, 2006).

A pertinent question at this juncture is: why do many students prefer a particular subject and not the other? Several attempts have been made to formulate a comprehensive theory of academic choice. Most models of choice processes assume that individuals make rational decisions about alternatives on the basis of information on the values that these represent for them and their estimated chance for success. Most variables in academic choice research tradition are of an ascriptive nature and are taken as motives for choosing. A distinction is usually made between intrinsic value (interest and pleasure) and utilitarian value (relevance).

The relationship between interest, attributed future relevance and success expectancy (estimated feasibility) and choice intentions and actual choices, has often been shown (e.g. Valentine, 1960; Eccles, Barber, Updegraff, \& O’Brien, 1995; Stokking, 2000). Many researchers' academic choice processes used Parsons/Eccles model (e.g. Meece et al. 1982 see, Stokking 2000). In this model, cognitions are postulated leading to the values and expectations mentioned in the preceding sections: perceptions, interpretations and attributions of experiences, and socializing influences. In this tradition, factors that primarily lead to the expectance of success are elaborated upon, with the help of concepts 
such as observed task difficulty, individuals' own impressions of their capability and self confidence. The experiences that convey these cognitions are experiences of success (in school this is often related to marks). Exogenous determinants in the model are social background, ability and gender.

As pointed out by Stokking (2000), several remarks are called for. One, it is debatable whether the model is suitable as a theoretical model or should only be used as an arrangement of variables for the benefit of instrument construction and data analysis. Two, it is questionable whether the relations as depicted in the model only describe expected results on an aggregate level, or also processes on an individual level. Three, the question remains whether the model aims to describe both the maturing of students (a process of many years) and the process of making choices (often more bound to specific moments or short periods) and whether it accomplishes it. Four, some potentially important categories of variables are lacking in the model. In particular, influences that can appear during a choice process in a school (for example the social norms in a school - availability of functional science clubs) and the way a choice is made (the information involved and the way it is processed.

A review of relevant literature on choice processes in physics education at the international level, shows that interrelationship of such factors as interest (Stokking, 2000; Reid \& Skryabina, 2002; Sharp, 2004; Lavonen et al., 2005); perceived difficult nature of physics and prior achievement ( Iroegbu,1998; Woolnough, 1994; Sharp, Hutchinson, ; Reid \& Skryabina, 2002); perceived relevance of physics to professions and everyday life (Osborne \& Collins, 2000), self-concept (Lips, 2004); teacher-students' classroom and (or) laboratory interaction (Sjoberg, 2000; Kuti, 2006) teaching methods(Simon,2000; Adegoke 2003) with students' choice intentions and actual choice are well documented. This does not imply, however that other factors than those cited in the literature cannot be of influence.

As already stated, most models of academic choice processes show that the variable gender has little relation to the criterion variable when taking other predictors into account. The social background, often measured as the parents' educational level, is positively related to the choice of physics in some studies e.g. Gallager, 1994, while other studies disagree with it (Dekkers\& Smmets, 1997; Stokking, 2000). A cursory look at most models of academic choice processes shows that an important variable is missing. Almost all models of academic choice processes do not include the effect that availability of clubs and societies in schools can have on students' choice intentions and actual choices of school subjects.

The importance of clubs and societies (when they are available in schools) in arousing and re-awakening the interest of students in the study of basic core subjects such as mathematics, practical-oriented science and vocational subjects cannot be overemphasized. Clubs and societies when functional, as data from a Nigerian State Ministry of Education (Lagos State MOE Report, 2008) shows, can motivate more students to be more interested in schooling and also ensure an all - round development of students. This should be so, because clubs and societies in general provide opportunities for members to interact, as well as encourage healthy competitions between students and 
Determining Factors in Secondary School Students' Choice of Physics

Adegoke, B. A.

schools. In school settings, through opportunities for interactions which science clubs engender, students are provided the opportunity to share knowledge and experiences.

Through science clubs, students are provided the opportunities to interact with their colleagues even from other schools, share experiences, discuss problems, go on excursions, take part in exhibitions and quiz competitions. Students benefit from opportunities to discuss their ideas with their peers and through this, they will be able to see the value of different perspectives and refine their ideas. These activities enhance collaboration in learning as well as stimulate students' interest in physics. Awortwi (2008) while corroborating this assertion, called on physics teachers in Ghana to reactivate and form science clubs. According to Awotwi (2008), reactivating science clubs will aid the teaching and learning of physics as well as remove the phobia most students attach to physics. He went on further to say that the establishment of science clubs was the secret of many industrialized countries and therefore appealed to stakeholders to support their establishment in basic and second cycle institutions in Ghana. A similar view was held by Tyagi (2003) while commenting on the need for a comprehensive networking of science clubs in India. These are likely to be some of the factors that prompted the Federal Government of Nigeria through her Federal Ministry of Education (FME, 1989) to institute a science club known as Junior Engineers Technicians and Scientists (JETS) in all secondary schools in Nigeria. Yearly reports (FME, JETS Reports 2003-2007) on JETS activities however show that in most schools, this club only exists in name. Nevertheless yearly reports further indicate that in schools where JETS are functional and students are encouraged to participate actively in all the club's activities the enrolment figures of students in science classes as well as students performances in external examinations conducted by WAEC and NECO are higher than in schools where JETS are not functional.

Can it therefore be said that availability of functional science clubs and societies can be a potential determinant of students' choice of physics? Can schools woo more students into science class and in particular physics if science clubs and societies are available and functional in the school system? It is against this background that this study was undertaken. Because students' interest in physics learning is so important to future involvement in the subject, it is useful to know how availability of functional science clubs such as JETS can interrelate with interest to prod students into choosing physics at the senior secondary level.

Physics education has identified factors that interrelate with interest in physics learning which by implication determine students' actual choice of the subject: These include relevance to further studies/career; level of perceived difficult nature of the subject; previous level of achievement in physics; students biological sex; pedagogical skills of the teacher (the extent to which physics subject matter are clearly explained to the students by the teacher - clarity); interest in the context in which certain physics topics are met; as well as opportunities for performing experiments in the laboratory.

One important goal in the development of physics education at the global level has been to bridge the gender gap in physics (Institute of Physics, 2006). This is because an equal number of women and men in science and technology related occupations would promote 
a more equal society. It is likely that the number of girls taking physics can be increased if science clubs are available and girls are encouraged to participate actively in such science clubs. In view of this, it is important to see how the biological sexes of the students interrelate with availability of functional science clubs to make more girls choose physics.

In this study answers were sought to the following three research questions:

i. Does the obtained regression equation resulting from the set of the eleven predictor variables (i.e. availably of functional science clubs; membership of science clubs; pedagogical skills of the teacher - clarity; opportunities for experiments in school's laboratory; gender; relevance of physics to future career/ studies; self concept; interest ; previous score in physics ; parental level of education; and perceived difficult nature of physics) allow the prediction of students' choice of physics?

ii. Which of the eleven predictor variables are most influential in predicting students' choice of physics in senior secondary schools?

iii. Are there any predictor variables that do not contribute significantly to the prediction model?

\section{Methods}

\section{Participants}

Three hundred and eighty-four senior secondary school two students SS 2 were randomly selected from 14 public Senior Secondary Schools in Ibadan Educational Zone I, Oyo State, Nigeria. These served as participants. In each of the sampled schools, the intact class of science students was used. This consisted of 186 boys and 198 girls. The mean age of the students was 16.25 years (standard deviation $=0.46$ years).

\section{Materials}

A questionnaire titled "Assessing students' choice of physics" (ASCP, see the appendix) with a close response format as well as mark recording sheets were used for data collection. The ASCP was developed by building on the pattern of the instrument of Stokking (2000). It consisted of 3 sections (A, B, C). In section A, there were 4 items which required information on students' gender, fathers level of education, career aspiration, age, availability of functional science clubs in schools as well as membership of science clubs. For scoring, gender was rated as boys $=1$; girls $=2$; membership in science clubs was rated as: Yes $=2$; No $=1$; the students were asked to state the extent to which they participate in science clubs in their schools if science clubs are available. The answer modalities were: to a very great extent; to a small extent; not at all. Availability of functional science clubs in school was rated as: None $=0$; Math club only $=1$; JETS club only $=2$; Math and JETS clubs $=3$. Father's level of education was rated as: Post Graduate $=5 ;$ Graduate=4;Diploma=3; Senor School=2; Junior School=1, No formal Education $=0$. 
Determining Factors in Secondary School Students' Choice of Physics

Adegoke, B. A.

Section B covers 6 subsections and 24 items. A four point scale and two types of answer modalities were used. From "Strongly Agree" to "Strongly Disagree" i.e. SA, A; D; SD (sub sections I to III) and from "Always" to "Never" i.e. AL, SO, RA, NE (subsection IV). For positively stated items in subsections I to III scoring was in the order SA = 4; A $=3 ; \mathrm{D}=2 ; \mathrm{SD}=1$, while it was reversed for negatively worded items. Similarly in subsections II, for positively worded items, scoring was in the order of $\mathrm{AL}=4$; $\mathrm{SO}=3$; $\mathrm{RA}=2 ; \mathrm{NE}=1$, while it was reserved for negatively worded items. The Cronbach Alpha for the six subsections ranged from 0.74 to 0.81 .

Section $\mathrm{C}$ consisted of 4 items which served as the measures of the criterion variable. One, the students were asked whether they would include physics in their final subjects when making final choices at the point of registration for SSCE. The answer modalities were "Definitely Not" $=0$; "Probably Not" $=1$; "Probably" $=2$ and "Definitely Yes" $=3$. Two, they were asked to rate the three core science subjects (Biology; Chemistry; Physics) in the other of their preference for each of them. For the scoring, the most preferred was rated 2; the next most preferred was rated 1 , while the least preferred was rated 0 .

Three, each of the students was also asked what his or her reactions will be if the physics teacher disallows him or her to register for physics at the point of registration for SSCE. The answer modalities were: I will never agree with such a decision; I will take the teachers decision calmly and wait for another session; I will take the teachers decision calmly and never take physics in my life again. For scoring, the answer modalities were rated as $2 ; 1 ; 0$ in the other in which the statements were stated.

Four, the students were also asked to state the level to which they hope to be involved in physics in the future. The answer modalities were; to a very large extent; to a small extent; not at all. For scoring, the answer modalities were rated as $2 ; 1 ; 0$ respectively.

Participants' mean annual score in physics examinations in SSII were obtained from the principals of each school. In Nigeria as well as in other English speaking West African countries that jointly present candidates for SSSCE, the levels of achievement are classified using stanine viz: A1, B2, B3, C4, C5, C6, D7, P8, and F9 - (arranged in descending order). For the purpose of this study, the participants grade points in physics in SSII were rated as $\mathrm{A} 1=18 ; \mathrm{B} 2=16 ; \mathrm{B} 3=14 ; \mathrm{C} 4=12 ; \mathrm{C} 5=10 ; \mathrm{C} 6=8 ; \mathrm{D} 7=6$; $\mathrm{P} 8=$ $4 ; \mathrm{F} 9=0$.

\section{Procedure}

All the participants completed the questionnaire in their classrooms during the period allotted to Physics on the official school time table. In each school, the administration of the test lasted about 60 minutes. The physics teacher in each of the schools and I were involved in the data collection. I explained what each statement in the questionnaire meant. The data collection lasted for 19 days during the 1st term of 2007/2008 (September to December, 2007) academic session in Oyo State, Nigeria. 
Variables involved in the study

Predictors Variables: Eleven were used. These included membership of science clubs; career aspiration ; availability of functional science clubs; perceived relevance of physics to future studies; gender; perceived difficult nature of physics; interest in physics; previous score in physics examination; self concept ; parents level of education; clarity; and opportunities to perform experiments in the school laboratory.

Dependent Variable: This was choice of physics (as measured by the four items in ASCP questionnaire - see the appendix).

\section{Analysis of Data}

Table 1 presents the means and the standard deviations on each of the 11 predictors as well as the choice of physics.

Table $1 \quad$ Means and Standard Deviation on Variables

\begin{tabular}{llcc}
\hline S/No. & Variables & Mean & SD \\
\hline 1 & Clarity & 11.24 & 3.50 \\
2 & Opportunities for experiments & 9.63 & 3.89 \\
3 & Career aspiration & 2.20 & 0.57 \\
4 & Membership in science clubs & 1.58 & 0.49 \\
5 & Availability of science clubs. & 2.84 & 0.39 \\
6 & Perceived relevance to future career & 13.87 & 1.95 \\
7 & Gender & 1.45 & 0.50 \\
8 & Interest & 11.57 & 3.52 \\
9 & Perceived difficult nature of physics & 5.18 & 1.39 \\
10 & Self-concept & 11.37 & 3.30 \\
11 & Previous score in physics & 8.95 & 2.70 \\
12 & Choice of physics & 3.88 & 0.60 \\
\hline
\end{tabular}

Using (SPSS Version 15), a standard multiple regression procedure was carried out to determine which of the eleven predictor variables of students' choice of physics were important. Inter correlations among the test variables were also calculated. A tolerance diagnostic was computed for each variable to determine whether multi co-linearity among the predictors might exist. For all coefficient the tolerance factor was greater than 0.30 (range $0.32-0.93$ ). With the use of a $\mathrm{p}<0.001$ criterion for Mahalanobis distance, no outliers among the cases were found. No cases had missing data. 
Determining Factors in Secondary School Students' Choice of Physics

Adegoke, B. A.

\section{Results}

Regression results as shown in Table 3 indicate that the overall model of the eleven predictor variables significantly predicts students' choice of physics, R2 $=0.069, R_{a d j}^{2}=$ $0.834, \mathrm{~F}(11,372)=2.494, \mathrm{p}=0.005$. This model accounts for $6.9 \%$ of the variance observed in the students' choice of physics at the senior secondary school level.

A summary of the regression coefficients is presented in Table 3 and it indicates that only 4 variables significantly contributed to the model. These are, clarity (the extent to which to the teacher clearly presents the content of physics to the students $\beta=-.284, \mathrm{t}(372)=-$ $3.009, \mathrm{p}=.003$; membership in science clubs $\beta=.160, \mathrm{t}(372)=2.603, \mathrm{p}<.05$; availability of functional science clubs $\beta=.131, \mathrm{t}(372)=2.313, \mathrm{p}<.05$; perceived difficult nature of physics $\beta=.113, \mathrm{t}(372)=-2.101, \mathrm{p}<.05$.

Table 2 Inter-correlation matrix

\begin{tabular}{|c|c|c|c|c|c|c|c|c|c|c|c|c|c|}
\hline & & 1 & 2 & 3 & 4 & 5 & 6 & 7 & 8 & 9 & 10 & 11 & 12 \\
\hline 1 & Clarity & 1.000 & & & & & & & & & & & \\
\hline 2 & $\begin{array}{l}\text { Opportunity for } \\
\text { experiments }\end{array}$ & .082 & 1.000 & & & & & & & & & & \\
\hline 3 & Career aspiration & .122 & .268 & 1.000 & & & & & & & & & \\
\hline 4 & $\begin{array}{l}\text { Membership in } \\
\text { science clubs }\end{array}$ & .311 & .158 & -.077 & 1.000 & & & & & & & & \\
\hline 5 & $\begin{array}{l}\text { Availability of } \\
\text { science clubs. }\end{array}$ & -.140 & -.018 & .092 & .041 & 1.000 & & & & & & & \\
\hline 6 & $\begin{array}{l}\text { Perceived } \\
\text { relevance to future } \\
\text { career }\end{array}$ & .103 & -3.81 & -.276 & -.211 & -.014 & 1.000 & & & & & & \\
\hline 7 & Gender & -.241 & -.377 & -.276 & -.089 & .069 & .310 & 1.000 & & & & & \\
\hline 8 & Interest & .769 & -.124 & .151 & .198 & -.139 & .115 & -.212 & 1.000 & & & & \\
\hline 9 & $\begin{array}{l}\text { Perceived difficult } \\
\text { nature of physics }\end{array}$ & -.176 & .116 & .074 & .153 & .176 & .116 & -.160 & -.150 & 1.000 & & & \\
\hline 10 & Self-concept & .724 & .305 & .211 & .331 & -.061 & -.039 & -.424 & .619 & -.005 & 1.000 & & \\
\hline 11 & $\begin{array}{l}\text { Previous score in } \\
\text { physics }\end{array}$ & .350 & -.015 & -.056 & .333 & -.353 & .79 & -.095 & .272 & -.070 & .381 & 1.000 & \\
\hline 12 & Choice of Physics & -.090 & -.025 & -.019 & .106 & .139 & -.032 & -.057 & -.020 & -.036 & -.019 & .010 & 1.000 \\
\hline
\end{tabular}


Table 3: $\quad$ Standard Multiple Regression of the 11 Predictor Variables on Choice of Physics

\begin{tabular}{lccccc}
\hline & $\mathrm{B}$ & $\beta$ & $\mathrm{t}$ & $\mathrm{P}$ & Bivariate $\mathrm{r}$ \\
\hline Constant & 3.622 & - & 7.569 & 0.000 & - \\
Clarity & $-4.863 \mathrm{E}-02$ & -.284 & -3.009 & $.003^{*}$ & -.090 \\
Opportunity for experiments & $-5.045 \mathrm{E}-02$ & -.033 & -.501 & .617 & -.025 \\
Career aspiration & $-1.126 \mathrm{E}-02$ & -.011 & -.189 & .850 & -.019 \\
Membership in science clubs & .195 & .160 & 2.603 & $.010^{*}$ & .106 \\
Availability of science clubs. & .201 & .131 & 2.313 & $.021^{*}$ & .139 \\
Perceived relevance to future career & $4.690 \mathrm{E}-03$ & .015 & .252 & .801 & -.032 \\
Gender & -.123 & -.102 & -1.656 & .099 & -.057 \\
Interest & $1.981 \mathrm{E}-02$ & .116 & 1.330 & .184 & -.020 \\
Perceived difficult nature of physics & $-4.877 \mathrm{E}-02$ & -.113 & -2.101 & $.036^{*}$ & -.036 \\
Self-concept & $4.057 \mathrm{E}-03$ & .022 & .254 & .797 & -.019 \\
Previous score in physics & $9.303 \mathrm{E}-03$ & .042 & .669 & .504 & .010 \\
\hline
\end{tabular}

$* \mathrm{P}<0.05, \mathrm{R}^{2}=0.069, R_{a d j}^{2}=0.041, \mathrm{R}=0.262$

\section{Discussion}

Findings of this study showed that a linear combination of the 11 independent variables can predict students' choice of physics in secondary school education. However, memberships in science clubs, availability of functional science clubs, and perceived difficult nature of physics as well as clarity (the extent to which the contents of the subject matter are clearly explained by the teacher) were best predictors.

The importance of science clubs cannot be overemphasized. The findings of this study lay credence to the views of Anderson (2008), Awortwi (2007) and Tyagi (2003) that science clubs and societies when available in a school and students are encouraged to join and participate in the activities of such clubs, they provide good milieu for stimulating students' interest in science subjects. This should be so, because clubs generally provide opportunities for members to interact and through interaction, knowledge and experiences are shared. Through science clubs, students (members) are provided the opportunities to interact with their colleagues, share experiences, discuss problems, go on excursions, take part in exhibitions and quiz competitions. All these are likely to stimulate students' interest in physics.

Generally, reflecting on published research at the global level, it is quite evident that the perceived difficult and boring nature of physics is the explanation given by students who would not have willingly chosen physics given the opportunity (Woolnough, 1994; Stokking, 2000; Institute of Physics 2006). Therefore, as the findings of this study also showed, credence is laid to the fact that, the more a student perceives physics to be 
difficult, the less the probability of his or her choosing it as a school subject as well as his or her enrolling in it. In actual fact, the study of physics requires math ability as well as reasoning ability, and which from my experiences as a physics teacher at the secondary school level of about two decades, many students appear to lack. Undoubtedly, many students have problem with the logical-mathematical operations that are demanded in physics learning.

Of importance as the findings of this study show is the relationship between the pedagogical techniques employed by the teacher. The type of classroom teacher - pupil interactions that are prevalent in the classroom may inhibit or facilitate students' learning; stimulate or discourage the students from choosing physics. Teachers that adopt integrative teaching style (maximizes students' opportunities to participate in the teaching and learning activities in the classroom) are more likely to facilitate students learning of physics and thereby motivate them to continue with physics in the future, while teachers that adopt dominative teaching style (lectures more and minimizes students' opportunities to participate in the teaching and learning activities in the classroom) are more likely to inhibit students' learning of physics. The findings of this study agree with that of Stokking (2000), Hort (2002), and Sharp (2004) who found that students' choice of physics is related to the pedagogical technique that the teacher employs in the classroom. In her study Sharp (2004) found that the students that she sampled acknowledged that, their learning in science would be supported by undertaking practical activities that involve solving rather than following recipe-type instructions. This, according to the students will enhance their interest in the subject. Angell, Guttersand, Herisken and Isnes (2004) reported that students want lessons to be more varied and more students centered. From the findings of this study, it appears that, the more the teachers present content of physics in manner that inhibit students understanding, the more they are likely to run away from offering physics. Therefore, to stimulate students' interest in physics, teachers need to explain, ask questions, allow students to participate in the teaching-learning activities and clarify issues. If this is done more and more students will be attracted to physics.

\section{Conclusions}

The results of this study point out the need for more effective guidance and counseling. A situation where a large number of boys and girls even in science classes still believe that physics is difficult, boring and that they may not likely succeed in it is a ground for concern indeed. To maintain students' interest and motivation in physics it is important that teachers and school counselors provide the students with enough experiences that will enable them see themselves as competent even in the subject. Students need to be propelled towards the feelings that they can do physics if they decide to continue to study it.

The evidence of the study suggests that all schools should be encouraged to set up science clubs and societies. More importantly, all students in all schools world-wide should be encouraged to participate in science clubs. Availability of functional science clubs and societies as well as giving broad opportunities to the students to join and 
participate fully in the activities of such clubs are likely to encourage more students' participation in physics.

\section{References}

Adenipekun, O (2008) Lagos government resuscitates literary debate in senior secondary schools. Culled from http://odili.net/news/source/2008/jun/19/317.html.

Adegoke, B.A. (2000). Test response mode, numerical ability and gender as determinants of senior secondary schools students' cognitive achievement in physics. Unpublished Master's Project, University of Ibadan, Ibadan, Nigeria.

Anderson, R. (2008) Science clubs in Rolla Middle Schools, Rolla Missouri. Culled from http: //rolla.k 12.mo.us/schools/rollam middle-schools

Angell, C., Guttersand, O., Henriksen, E. K. \& Isnes, A. (2004). Physics: Frightful, but fun. Science and Education, 88(5), pp. 684-706.0

Awortwi, H. A., (2007) Establish science in schools -Retired Director of Education. Culled from http://www.modernghana.com/

Breakwell, G.M., Vignoles, V.L., Robertson, T. (2003). Stereotype and cross-category evaluations: The case of gender and science education. British Journal of Psychology, 94(4), pp. 437-455.

Cleaves, A. (2005). The formation of science choices in secondary schools. International Journal of Science Education, 27(4), pp. 471-486.

Melling, L. (2003). Subject choice and occupational aspirations among pupils at girl's schools. Pedagogy, Culture and Society, 11(3), pp. 425-442.

Gallagher, S. A., (1994). Middle school classroom predictors of science persistence. Journal of Research in Science Teaching. 31(7), pp.721-734

Hort, C. (1997). Framing curriculum discursively: Theoretical perspectives on the experience of VCE physics. International Journal of Science Education, 24(10), pp. 1055-1077.

Institute of Physics (2006). Girls in the physics classroom: A review of the research into the participation of girls in physics. Culled from http://www.iop.org/EJ/journal/PhysEd

Iroegebu, T.O. (1998). Problem-based learning, numerical ability and gender as determinants skill at senior secondary school physics in Ibadan. An unpublished doctoral thesis, University of Ibadan, Ibadan. 
Determining Factors in Secondary School Students' Choice of Physics

Adegoke, B. A.

Krogh, L.B. \& Thomsen, P. (2005). Studying students' attitude towards science from a cultural perspective but with a quantitative methodology: Border crossing into the physics classroom. International Journal of Science Education 27(3) 143-157.

Lavonen, J., Byman, R., Kalle, J., Meisalo, V. \& Uitto, A. (2005). Pupil interest in physics: A survey in Finland. NORDINA, 2, pp. 72-85.

Lips, H.M. (2004). The gender gap in possible selves: Divergence of academic self-views among high school and university students. Sex Roles, 50(5/6), pp. 357-371.

Meece, J. L., Eccles Parsons, j.,Kaczala, C. M. ,Goff ,S. B .,\& Futterman,R.(1982).Sex differences in math achievement toward a model of academic choice. Psychological Bulletin, 91(2), 324-348

Opara, J.R., (2004) .Refocusing research in science, technology and mathematics education in Nigeria: Issues, challenges and the way forward. 45th Annual Conference Proceedings of Science Teachers Association of Nigeria, 43-49

Osborne, J., Simon, S. \& Collins, S. (2003). Attitudes towards science: A review of the literature and its implications. International Journal of Science Education, 25(9), 1049-1079.

Reid, N., \& Skryabina, E.A. (2002). Attitudes towards physics. Research in Science and Technological Education 20(1), pp. 67-80.

Rewid, N. (2003). Gender and physics. International Journal of Science Education, 25(4) pp. 509-536.

Schachtel, E.G. (1959). Metamorphosis: On the development of affect, perception and memory. New York: Basic Books.

Sharp, C. Hutchison, D., Davis, C., \& Keys, W. (1996). The take up of advanced mathematics and science courses - summary report. National Foundation for Educational Research Report for SCAA 19.

Sharp, G. (2004). A longitudinal study investigating pupil attitudes towards their science learning experience from a gender perspective. Milton Kynes: Open University.

Stokking, K.M. (2000) Predicting the choice of Physics in secondary education. International Journal of Science Education, 22(12), pp. 1261-1283.

Tyagi, S. B.K., (2003) Network of Vigyan Prasar Science Clubs.Culled from http://www.vigyanprasar.gov.in/vipnet.htm

Valentine, C.W. (1960). Psychology and its learning on education. London: Methnen and Co. Ltd. 
Woolnough, B.E. (1994). Why students choose physics or reject it. Physics Education, 29 , pp. 368-374. 